\title{
EBMH
}

\section{Post-traumatic stress disorder increases the risk of new drug problems in young adults}

Grant J Devilly and Richard Gist

Evid. Based Ment. Health 2008;11;91

doi:10.1136/ebmh.11.3.91

Updated information and services can be found at:

http://ebmh.bmj.com/cgi/content/full/11/3/91

\section{These include:}

Data supplement

Rapid responses

Email alerting service "web only references"

http://ebmh.bmj.com/cgi/content/full/11/3/91/DC1

You can respond to this article at:

http://ebmh.bmj.com/cgi/eletter-submit/11/3/91

Receive free email alerts when new articles cite this article - sign up in the box at the top right corner of the article

Notes

To order reprints of this article go to:

http://journals.bmj.com/cgi/reprintform

To subscribe to Evidence-Based Mental Health go to:

http:/journals.bmj.com/subscriptions/ 


\section{Post-traumatic stress disorder increases the risk of new drug problems in young adults}

\section{QUESTION}

Question: Is post-traumatic stress disorder (PTSD) associated with risk of new drug problems?

People: 988 young adults (aged 19-24 years) who had enrolled in a large cohort study while in first grade and followed through primary and middle school and on into adulthood. Of the original 2311 participants, only those at risk of a new drug use disorder (those without lifetime DSMIV drug dependence, and who did not have clinical features of DSM-IV drug abuse or dependence in the previous 12 months) were included in this study. Due to funding problems, not all of these 1436 people were followed up and 988 were included in the final analysis.

Setting: Participants recruited in 19 primary public schools in 5 urban areas in a large city in the USA; enrolment 1985-6, follow-up to 2002.

Risk factors: The main risk factors of interest were lifetime exposure to at least one DSM-IV-qualifying traumatic event in the absence of post-traumatic stress disorder (PTSD), and PTSD following exposure to a traumatic event (diagnosed using WHO Composite International Diagnostic Interview). Family socioeconomic status, conduct problems, cognitive ability and academic achievement and risk-taking at the time of school entry were included in regression models as potential confounders, as were gender, age, ethnicity and the number of years of education completed.

Outcomes: Incident cases of drug abuse or dependence (according to DSM-IV). The outcome was defined in one of four ways: drug abuse or dependence-1 or more DSM-IV clinical features of drug abuse or 2 or more DSM-IV clinical features with respect to any of 12 illegal or prescription drugs; drug abuse - 1 or more DSM-IV clinical features of drug abuse (without the presence of DSM-IV drug dependence); drug dependence-3 or more DSM-IV clinical features of drug dependence with respect to any of 12 illegal or prescription drugs (with or without DSM-IV drug abuse); or emerging drug dependence problems - 1 or 2 newly incident clinical features of drug dependence without the presence of clinical features of drug abuse.

\section{METHODS \\ Design: Prospective cohort study. \\ Follow-up period: One year.}

\section{MAIN RESULTS}

Overall, drug abuse or dependence was more than 4 times more likely in young adults with PTSD than in those with no trauma exposure (RR 4.9, 95\% CI 1.6 to 15.2). Exposure to a traumatic event in the absence of PTSD was not associated with an increase in risk of drug abuse or dependence (RR 2.4, 95\% CI 0.9 to 6.3). PTSD also increased the risk of emerging drug problems (that is, no formal DSM-IV diagnosis) compared to no trauma exposure (RR 4.9, 95\% CI 1.2 to 20.1).

\section{CONCLUSIONS}

PTSD, but not trauma only, is associated with subsequent drug use disorders even after adjusting for early life experiences.

\section{ABSTRACTED FROM \\ Reed PL, Anthony JC, Breslau N. Incidence of drug problems in young adults exposed to trauma and Posttraumatic stress disorder: do early life experiences and predispositions matter? Arch Gen Psychiatry 2007;64:1435-42.}

Correspondence to: Philip L Reed, PhD, Biomedical Research and Informatics Center, Michigan State University, 100 Conrad Hall, East Lansing, MI 48824-1327, USA; reedph@ht.msu.edu

Source of funding: National Institute of Mental Health and the National Institute on Drug Abuse.

- Additional notes and references are published online only at http://ebmh.bmj.com/ content/vol11/issue3
S ince its inception, post-traumatic stress disorder (PTSD) has been a nosological anomaly. Like the euphemistic characterisation of a camel as "a horse designed by committee", its conceptual anatomy was cobbled from elements that didn't readily fit. Although it functions well in most situations, it is an ungainly creature overall.

Increasingly sophisticated and longitudinal empirical programmes have pursued its central constructs and are helping build a more coherent and grounded picture of traumatic reactivity. Galea and colleagues greatly refined our understanding of reactivity and refraction, demonstrating that fewer civilians showed "caseness" after the 9/11 attacks in the USA than was widely expected ${ }^{1}$ and that $>90 \%$ resolved to subclinical levels between the current duration criterion (4 weeks) and the original DSM-III criterion (6 months). ${ }^{2}$ Breslau and colleagues traced key constructs such as the "clinically significant distress/ impairment" criterion, application of which reduced overall incidence by $30 \%$ but yielded greater severity and chronicity among those retained. ${ }^{3}$ They also reported, in contrast to widely accepted notions, that prior exposure to traumata increased vulnerability only where prior reactivity reached clinical proportions, ${ }^{4}$ suggesting that vulnerability may be more a feature of individual patterns of reactivity than of exposure per se. In this paper, they report that prior PTSD, rather than simply prior trauma exposure, predicted increased vulnerability to drug abuse and dependence. This suggests that drug abuse is likely consequential to the distress of trauma rather than purely a situational or lifestyle correlate.

The initial construction of PTSD proclaimed aetiological genesis as situational rather than dispositionalan example of the attribution error long known to social psychologists. Clearly, both factors matter and clinging solely to one while cleaving the other does little to provide a valid or balanced view of behaviour and its origins. Kessler's finding ${ }^{5}$ that $79-88 \%$ of those presenting with PTSD also presented comorbid conditions questions whether clinically significant PTSD is so cleanly a situational reaction as has typically been argued; Breslau's work helps us better understand which interactions apply. Screening and interventions that more appropriately target those whose post-event disequilibria interacts with preexisting or consequential comorbid conditions are increasingly indicated and should become a focus. Such research will ultimately lead to detection and prevention strategies.

\section{Grant J Devilly, PhD}

Department of Psychology, The University of Melbourne, Melbourne, Australia

\section{Richard Gist, PhD}

Kansas City, Missouri Fire Department and Department of Preventive Medicine, Kansas City University of Medicine and Biosciences, Kansas City, USA

Competing interests: None. 